\title{
Green tea as an effective antimicrobial for urinary tract infections caused by Escherichia coli
}

\author{
Wanda Reygaert ${ }^{1}$ * and Ilir Jusufi ${ }^{2}$ \\ ' Department of Biomedical Sciences, Oakland University William Beaumont School of Medicine, Rochester, MI, USA \\ ${ }^{2}$ Biomedical Diagnostic and Therapeutic Sciences Program, Oakland University School of Health Sciences, Rochester, MI, USA
}

\section{Edited by:}

Nicoletta Belletti, Institute for Food Research and Technology, Spain

\section{Reviewed by:}

Nicoletta Belletti, Institute for Food Research and Technology, Spain Antonio Valero, University of Cordoba, Spain

\section{${ }^{*}$ Correspondence:}

Wanda Reygaert, Department of Biomedical Sciences, Oakland University William Beaumont School of Medicine, 2200 North Squirrel Road, Rochester, MI 48309, USA e-mail: reygaert@oakland.edu

\begin{abstract}
Background: Urinary tract infections (UTIS) are a very most common type of infection worldwide, and result in billions of dollars in medical care costs. Escherichia coli is the infective agent for $80-90 \%$ of all UTIs. Green tea, derived from leaves of the Camellia sinensis plant has been shown to have various potential health benefits (e.g., cardiovascular disease and cancer). The major beneficial components of green tea have been characterized, and are now known to be polyphenolic catechins. The main catechins in green tea are (-)-epicatechin-3-gallate, (-)-epigallocatechin (EGC), (-)-epicatechin, and (-)-epigallocatechin-3-gallate (EGCG). EGCG and EGC have been shown to have the greatest antimicrobial effects, but only EGC has been shown to be excreted in urine. Isolates of E. coli from UTIs collected between 2007 and 2008 were characterized for antimicrobial resistance to standard drugs. Then 80 of these isolates, representing a wide spectrum of antimicrobial susceptibility patterns, were selected for testing using an extract of green tea.
\end{abstract}

Results: The concentrations of green tea extract tested were $0,2.5,3.0,3.5$, and $4.0 \mathrm{mg} / \mathrm{ml}$. All of the strains tested, except one, had minimum inhibitory concentrations (MICs) of $\leq 4.0 \mathrm{mg} / \mathrm{ml}(99 \%)$, with $94 \%$ of the isolates having an MIC of $\leq 3.5 \mathrm{mg} / \mathrm{ml}, 76 \%$ of the isolates having an MIC of $\leq 3.0 \mathrm{mg} / \mathrm{ml}, 40 \%$ of the isolates having an $\mathrm{MIC}$ of $\leq 2.5 \mathrm{mg} / \mathrm{ml}$. Two control strains varied in susceptibility, one having an MIC of $\leq 2.5 \mathrm{mg} / \mathrm{ml}$, and the other having an $\mathrm{MIC}$ of $\leq 3.5 \mathrm{mg} / \mathrm{ml}$.

Conclusion: Since EGC has been shown to have antimicrobial effects on E. coli, and EGC has been shown to be excreted in the urine in a high enough concentration to potentially be effective as an antimicrobial; these $\mathrm{MIC}$ results suggest that ingesting green tea could have potential antimicrobial effects on UTIs caused by E. coli.

Keywords: green tea, antimicrobial, urinary tract infections, Escherichia coli, antimicrobial resistance

\section{INTRODUCTION}

Urinary tract infections (UTIs) are the second most common type of infection found in any organ system, and the most common type of nosocomial infection (Carson and Naber, 2004). These UTIs are responsible for over eight million doctors visits per year in the U.S. (National Institute of Diabetes and Digestive and Kidney Diseases, 2005), and result in medical costs of over six billion dollars worldwide per year (Anderson et al., 2004b; Kucheria et al., 2005). Most UTIs (80-90\%) are the result of infections with Escherichia coli (Karlowsky et al., 2002). Non-pathogenic strains of E. coli are an important part of the normal flora in the human intestinal tract.

The strains of $E$. coli that infect the urinary tract are categorized as uropathogenic E. coli (UPEC; Kaper et al., 2004). The UPEC are able to produce special surface proteins (adhesins) that allow them to attach to and invade the epithelial cells that line the urinary bladder (Anderson et al., 2004a; Schaeffer et al., 2004; Kau et al., 2005; Marrs et al., 2005). If the infection is not eradicated while it is in the bladder (uncomplicated UTI), some strains of UPEC may then travel up the ureters to the kidneys and cause even more severe infections (complicated UTIs), which can lead to renal damage and possibly renal failure (Kaper et al., 2004; Pichon et al., 2009). There are 14 serogroups of UPEC that are most commonly found in UTIs, and $75 \%$ of UTIs have been shown to be caused by serogroups 04 , 06, 014, 022, 075, and 083 (Stenutz et al., 2006; Li et al., 2010). The most common serogroups involved in causing UTIs worldwide are 02, 04, 06, and 075 (George and Manges, 2010). In the U.S., $49 \%$ of UTIs in women have been found to be caused by serogroups 06,04 , and 075 , in descending frequency of occurrence (Vosti, 2007).

The antimicrobial agents that have traditionally been used to treat UTIs ( $\beta$-lactams, fluoroquinolones, trimethoprimsulfamethoxazole, nitrofurantoin, etc.) are becoming less effective (Warren et al., 1999; Wagenlehner and Naber, 2005). In recent years, the number of antimicrobial resistant strains of $E$. coli isolated from UTIs has been increasing, including resistance to antimicrobial agents normally used to treat UTIs (Sahm et al., 2001; Kahlmeter, 2003; Muratani and Matsumoto, 2004; Landgren etal., 2005; Zhanel etal., 2006). Even though scientists are constantly working to develop new and improved 
antimicrobials, almost as soon as a new drug is released, the bacteria show resistance to it. These isolates are also showing resistance to drug combinations such as amoxicillin/clavulanic acid, piperacillin/tazobactam, and trimethoprim/sulfamethoxazole (Dias etal., 2009; Gündoğdu et al., 2011; Jadhav et al., 2011; Molina-López et al., 2011; Oliveira et al., 2011).

Green tea is derived from non-fermented leaves of the Camellia sinensis plant. Oolong and black tea are made from fermented leaves of the same plant. Green tea has been a favored drink, traditionally, in Asian countries. Because of studies that have shown the potential health benefits of green tea, it is now gaining worldwide popularity as a drink that is important in preventative medicine. Studies using green tea have shown it to have potential benefits, most notably in: cardiovascular disease, cancer, diabetes, obesity, oral health, bone health, and cognitive function (McKay and Blumberg, 2002; Cabrera et al., 2006; Chacko etal., 2010; Mak, 2012). In addition, green tea has been shown to have antimicrobial effects (Yam et al., 1997; Taylor etal., 2005; Friedman, 2007; Song and Seong, 2007).

The components in green tea that are responsible for these various effects are polyphenols (also known as catechins). The main catechins in green tea are (-)-epicatechin (EC), (-)epicatechin-3-gallate (ECG), (-)-epigallocatechin (EGC), and (-)-epigallocatechin-3-gallate (EGCG), which have been shown to make up approximately $30-40 \%$ of the water-soluble solids in brewed green tea (Wang and Ho, 2009). Three of these catechins, ECG, EGC, and EGCG have been show to have antimicrobial effects against a wide variety of microorganisms (Yam et al., 1997; Taguri et al., 2004, 2006; Taylor et al., 2005; Friedman, 2007; Song and Seong, 2007). The two found in the highest amounts in green tea are EGC and EGCG. Both of these are excreted in bile, but EGC is also excreted in the urine, suggesting the possibility for green tea having antimicrobial activity in UTIs (Yang etal., 1998; Lee etal., 2002; Cabrera et al., 2006; Luo et al., 2006). Most of the studies on how these compounds accomplish the antibacterial activity have focused on EGCG. Because EGCG is not excreted in the urine (Yang et al., 1998), it is not the compound of interest for this study. One study has found that EGC is able to bind to the ATP binding site of the bacterial gyrase B subunit, thus inhibiting gyrase activity (Gradišar et al., 2007). The aim of the current study was to investigate the susceptibility of UPEC strains, representing a wide variety of antimicrobial susceptibility patterns, to green tea.

\section{MATERIALS AND METHODS BACTERIA STRAINS}

The bacterial strains used in this study were part of a research collection of E. coli isolated from UTI cultures during the years of 2007-2008. There were 80 isolates selected from this collection that represented a wide spectrum of antimicrobial susceptibility patterns; in addition, two control strains that were susceptible to all the clinically tested (prior to this study) antimicrobials were selected. Table 1 shows the antimicrobial agents tested and frequency of the strains that were resistance to each drug.
Table 1 | Frequency of the antimicrobial resistance of $E$. coli strains used in this study.

\begin{tabular}{ll}
\hline Antimicrobial & Resistant, $\boldsymbol{n}$ (\%) \\
\hline Ampicillin & $63(78)$ \\
Piperacillin & $57(71)$ \\
Ampicillin/sulbactam & $53(66)$ \\
Tetracycline & $35(44)$ \\
Ciprofloxacin & $33(41)$ \\
Trimethoprim/sulfamethoxazole & $29(36)$ \\
Cefazolin & $12(15)$ \\
Gentamicin & $12(15)$ \\
Tobramycin & $10(13)$ \\
Cefuroxime & $9(11)$ \\
Amoxicillin/clavulanic acid & $7(9)$ \\
Aztreonam & $5(6)$ \\
Ceftriaxone & $5(6)$ \\
Nitrofurantoin & $5(6)$ \\
Cefepime & $4(5)$ \\
Norfloxacin & $3(4)$ \\
Piperacillin/tazobactam & $2(3)$ \\
\hline
\end{tabular}

\section{GREEN TEA EXTRACT}

A standardized green tea (C. sinensis) extract (standardized to 7.0\% polyphenols) was obtained from Swanson Vitamins ${ }^{\circledR}$. The plant extract was prepared in water.

\section{MEDIA}

The media used in these experiments was Luria-Bertani (LB) broth (Teknova brand), and dehydrated Müller-Hinton agar (MHA; BD brand).

\section{MINIMUM INHIBITORY CONCENTRATION DETERMINATION}

The minimum inhibitory concentration (MIC) of the green tea extract was determined by agar dilution method. MHA plates that contained various concentrations of green tea extract $(0$, $2.5,3.0,3.5$, and $4.0 \mathrm{mg} / \mathrm{ml}$ ) were prepared. Suspensions of 0.5 McFarland standard dilutions (equal to $1.5 \times 10^{8}$ cells $/ \mathrm{ml}$ ) were prepared from bacterial cultures grown overnight in LB broth. A $10^{-4}$ dilution of these suspensions was prepared, and $100 \mu \mathrm{l}$ of dilution per plate was inoculated using a spread plate technique (plated concentration equals $1.5 \times 10^{3}$ cells). Inoculated plates were incubated at $37^{\circ} \mathrm{C}$ for $48 \mathrm{~h}$, and on the basis of colony counts, the MIC was determined as the lowest concentration of green tea extract to show an inhibitory effect on growth of the bacteria (no colonies detected). Each strain was tested three times.

\section{RESULTS}

\section{MIC DETERMINATION}

The MICs and susceptibility results are as follows: 99\% were susceptible to the green tea extract at a concentration of $\leq 4.0 \mathrm{mg} / \mathrm{ml}$ 
Table 2 | Minimum inhibitory concentrations for total green tea extract (GTE) and the EGC component.

\begin{tabular}{lllll}
\hline Component & \multicolumn{4}{c}{ Number of isolates tested (\% out of 79) } \\
\cline { 2 - 5 } & $\mathbf{3 2}(\mathbf{4 0 \% )}$ & $\mathbf{2 9}(\mathbf{3 7 \%})$ & $\mathbf{1 4}(\mathbf{1 8} \%)$ & $\mathbf{4}(\mathbf{5 \%})$ \\
\hline Total GTE $(\mathrm{mg} / \mathrm{ml})$ & $\leq 2.5$ & $\leq 3.0$ & $\leq 3.5$ & $\leq 4.0$ \\
EGC $(\mu \mathrm{g} / \mathrm{ml})$ & $\leq 450$ & $\leq 540$ & $\leq 630$ & $\leq 720$ \\
\hline
\end{tabular}

(one strain was not susceptible at even $4.0 \mathrm{mg} / \mathrm{ml}$ ); $94 \%$ were susceptible at $\leq 3.5 \mathrm{mg} / \mathrm{ml} ; 76 \%$ were susceptible at $\leq 3.0 \mathrm{mg} / \mathrm{ml}$; $40 \%$, were susceptible at $\leq 2.5 \mathrm{mg} / \mathrm{ml}$; The control strains varied; one being susceptible at $\leq 2.5 \mathrm{mg} / \mathrm{ml}$ and the other susceptible at $\leq 3.5 \mathrm{mg} / \mathrm{ml}$. Table 2 shows the MIC results for the 79 strains that were susceptible at $\leq 4.0 \mathrm{mg} / \mathrm{ml}$.

\section{DISCUSSION}

The green tea extract was shown to have an inhibitory effect on the growth of E. coli strains isolated from UTIs. The MIC results can be adjusted to reflect the EGC content, using a value of $18 \%$ EGC as the content in total green tea polyphenols (Vuong et al., 2011). That makes the adjusted results as follows: $40 \%$ of strains tested were susceptible at a concentration of EGC at $\leq 0.45 \mathrm{mg} / \mathrm{ml}$ $(450 \mu \mathrm{g} / \mathrm{ml}) ; 36 \%$ susceptible at $\leq 0.54 \mathrm{mg} / \mathrm{ml}(540 \mu \mathrm{g} / \mathrm{ml}) ; 18 \%$ susceptible at $\leq 0.63 \mathrm{mg} / \mathrm{ml}(630 \mu \mathrm{g} / \mathrm{ml})$; and $5 \%$ susceptible at $\leq 0.72 \mathrm{mg} / \mathrm{ml}(720 \mu \mathrm{g} / \mathrm{ml})$. Since all of the strains tested (99\%) were susceptible at a concentration of $\leq 0.72 \mathrm{mg} / \mathrm{ml}$, this suggests that EGC might be a good inhibitor of bacterial growth. Table 2 shows the MIC data for total green tea extract and for the EGC component.

The data was collected by in vitro experiments, but the effect can be described using information that is known about the metabolism of EGC from green tea. The amount of green tea polyphenols that would be present in the urine, including the amount of EGC, will vary according to the origin of the tea. It has been found, for instance, that Japanese tea (an average of 15 teas) contains approximately $20 \mathrm{mg}$ of EGC per gram of dry tea (Vuong et al., 2011). An average cup of Japanese green tea is made with one tablespoon of dry tea (instructions from package of tea) which is

\section{REFERENCES}

Anderson, G. G., Dodson, K. W., Hooton, T. M., and Hultgren, S. J. (2004a). Intracellular bacterial communities of uropathogenic Escherichia coli in urinary tract pathogenesis. Trends Microbiol. 12, 424-430. doi: 10.1016/j.tim.2004. 07.005

Anderson, G. G., Martin, S. M., and Hultgren, S. J. (2004b). Host subversion by formation of intracellular bacterial communities in the urinary tract. Microbes Infect. 6, 1094 1101. doi: 10.1016/j.micinf.2004 05.023

Cabrera, C., Artacho, R., and Giménez, R. (2006). Beneficial effects of green tea - a review. J. Am. Coll. Nutr. 25, 79-99.

Carson, C., and Naber, K. G. (2004). Role of fluoroquinolones in the treatment of serious bacterial urinary tract infections. Drugs 64, 1359-1373. doi: $10.2165 / 00003495-$ 200464120-00007

Chacko, S. M., Thambi, P. T., Kuttan, R., and Nishigaki, I. (2010). Beneficial effects of green tea: a literature review. Chin. Med. 5, 13. doi: 10.1186/1749-8546-5-13

Cho, Y. S., Schiller, N. L., Kahng, H. Y., and Oh, K. H. (2007). Cellular responses and proteomic analysis of Escherichia coli exposed to green tea polyphenols. Curr. Microbiol. 55,

equivalent to approximately $7.5 \mathrm{~g}$ of dry tea (a package of $60 \mathrm{~g}$ of dry tea makes eight cups). That equates to approximately $150 \mathrm{mg}$ of EGC per cup of Japanese green tea.

Urinary excretion after a single ingested dose of EGC has been shown to peak at $8 \mathrm{~h}$ after ingestion, with levels in the urine reaching to 3.0-5.0 $\mathrm{mg}$ (Yang et al., 1998). The amount of EGC excreted after ingestion of one cup of tea (as described above) should equal approximately $3.5 \mathrm{mg}$. Since the projected MICs for EGC are well below $3.5 \mathrm{mg}$, this suggests that even one cup of green tea could have an effect on a urinary tract pathogen, and drinking multiple cups over the course of a day could possibly provide a prolonged effect. Additional studies testing the in vivo effect of drinking green tea on UTIs could be useful for determining if the effects observed in this study have medical significance.

Studies have shown that concentrations of $500 \mu \mathrm{g}$ of tea polyphenols can inhibit the growth of E. coli, and that concentrations of $\geq 5000 \mu \mathrm{g}$ are considered bactericidal. This effect is believed to be due to the fact that tea polyphenols down regulate the production of proteins such as EF-2 (elongation factor for protein translation); proteins involved in phospholipid, carbon, and energy metabolism; and production of proteins involved in amino acid biosynthesis (Cho et al., 2007).

There was no correlation between MIC values in this study and the antimicrobial resistance of the isolates. Each level of MIC contained a variety of antimicrobial resistance patterns.

Another set of studies that would be interesting and potentially useful would be to test EGC and several of the standard antimicrobial agents used to treat UTIs to determine if there might be synergism between EGC and any of the antimicrobial agents. Studies have been done that show the ability of green tea to act synergistically with gentamicin and amikacin against $E$. coli (Neyestani et al., 2007).

\section{CONCLUSION}

The results of this study have shown that green tea can have an antimicrobial effect on E. coli bacteria that cause UTIs. This is the first time that green tea has been reported to have this kind of effect. The data also adds to the current information on the potential health benefits of green tea. It is our hope that these findings will encourage further studies on the antimicrobial potential of green tea and other plant components.

501-506. doi: 10.1007/s00284-0079021-8

Dias, R. C. S., Marangoni, D. V., Smith, S. P., Alves, E. M., Pellegrino, F. L. P. C., Riley, L. W. etal. (2009). Clonal composition of Escherichia coli causing community-acquired urinary tract infections in the State of Rio de Janeiro, Brazil. Microb. Drug Resist. 15, 303-308. doi: 10.1089/mdr.200 9.0067

Friedman, M. (2007). Overview of antibacterial, antitoxin, antiviral, and antifungal activities of tea flavonoids and teas. Mol. Nutr. Food Res. 51, 116-134. doi: 10.1002/ mnfr.200600173
George, D. B., and Manges, A. R. (2010). A systematic review of outbreak and non-outbreak studies of extraintestinal pathogenic Escherichia coli causing community-acquired infections. Epidemiol. Infect. 138, 1679-1690. doi: 10.1017/S0950268810001639

Gradišar, H., Pristovšek, P., Plaper, A., and Jerala, R. (2007). Green tea catechins inhibit bacterial DNA gyrase by interaction with its ATP binding site. J. Med. Chem. 50, 264-271. doi: 10.1021/jm0608170

Gündoğdu, A., Long, Y. B., Vollmerhausen, T. L., and Katouli, M. (2011). Antimicrobial resistance and distribution of sul genes and integron-associated intl genes among 
uropathogenic Escherichia coli in Queensland, Australia. J. Med. Microbiol. 60(Pt 11), 1633-1642. doi: 10.1099/jmm.0.034140-0

Jadhav, S., Hussain, A., Devi, S., Kumar, A., Parveen, S., Gandham, N., et al. (2011). Virulence characteristics and genetic affinities of multiple drug resistant uropathogenic Escherichia coli from a semi urban locality in India. PLoS ONE 6:e18063. doi: 10.1371/journal.pone.0018063

Kahlmeter, G. (2003). Prevalence and antimicrobial susceptibility of pathogens in uncomplicated cystitis in Europe. The ECO.SENS study. Int. J. Antimicrob. Agents 22(Suppl. 2), 49-52. doi: 10.1016/S09248579(03)00229-2

Kaper, J. B., Nataro, J. P., and Mobley, H. L. T. (2004). Pathogenic Escherichia coli. Nat. Rev. Microbiol. 2, 123-140. doi: 10.1038/nrmicro818

Karlowsky, J. A., Kelly, L. J., Thornsberry, C., Jones, M. E., and Sahm, D. F. (2002). Trends in antimicrobial resistance among urinary tract infection isolates of Escherichia coli from female outpatients in the United States. Antimicrob. Agents Chemother. 46, 2540-2545. doi: 10.1128/AAC.46.8.2540-2545.2002

Kau, A. L., Hunstad, D. A., and Hultgren, S. J. (2005). Interaction of uropathogenic Escherichia coli with host uroepithelium. Curr. Opin. Microbiol. 8, 54-59. doi: 10.1016/ j.mib.2004.12.001

Kucheria, R., Dasgupta, P., Sacks, S. H., Khan, M. S., and Sheerin, N. S. (2005). Urinary tract infections: new insights into a common problem. Postgrad. Med. J. 81, 83-86. doi: 10.1136/pgmj.2004.023036

Landgren, M., Odén, H., Kühn, I., Osterland, A., and Kahlmeter, G. (2005). Diversity among 2481 Escherichia coli from women with community-acquired lower urinary tract infections in 17 countries. J. Antimicrob. Chemother. 55, 928-937.

Lee, M. J., Maliakal, P., Chen, L., Meng, X., Bondoc, F. Y., Prabhu, S., et al. (2002). Pharmacokinetics of tea catechins after ingestion of green tea and (-)-epigallocatechin3-gallate by humans: formation of different metabolites and individual variability. Cancer Epidemiol. Biomarkers Prev. 11(Pt 1), 1025 1032.

Li, D., Liu, B., Chen, M., Guo, D., Guo, X., Liu, F., et al. (2010). A multiplex PCR method to detect 14 Escherichia coli serogroups associated with urinary tract infections. $J$. Microbiol. Methods 82, 71-77. doi: 10.1016/j.mimet.2010.04.008
Luo, H., Tang, L., Tang, M., Billam, M., Huang, T., Yu, J., et al. (2006). Phase II chemoprevention trial of green tea polyphenols in high-risk individuals of liver cancer: modulation of urinary excretion of green tea polyphenols and 8-hydroxydeoxyguanosine. Carcinogenesis 27, 262-268. doi: 10.1093/carcin/bgil47

Mak, J. C. (2012). Potential role of green tea catechins in various disease therapies: progress and promise. Clin. Exp. Pharmacol. Physiol. 39, 265-273. doi: 10.1111/j.1440-1681.2012.05673.x

Marrs, C. F., Zhang, L., and Foxman, B. (2005). Escherichia coli mediated urinary tract infections: are there distinct uropathogenic E. coli (UPEC) pathotypes? FEMS Microbiol. Lett. 252, 183-190. doi: 10.1016/j.femsle.2005.08.028

McKay, D. L., and Blumberg, J. B. (2002). The role of tea in human health: an update. J. Am. Coll. Nutr. 21, 1-13.

Molina-López, J., Aparicio-Ozores, G., Ribas-Aparicio, R. M., GavilanesParra, S., Chávez-Berrocal, M E., Hernández-Castro, R., et al. (2011). Drug resistance, serotypes, and phylogenetic groups among uropathogenic Escherichia col including O25-ST131 in Mexico City. J. Infect. Dev. Ctries. 5, 840-849. doi: 10.3855/jidc. 1703

Muratani, T., and Matsumoto, T. (2004). Bacterial resistance to antimicrobials in urinary isolates. Int. J. Antimicrob. Agents 24(Suppl. 1) S28-S31. doi: 10.1016/j.ijantimicag. 2004.02.001

National Institute of Diabetes and Digestive and Kidney Diseases. (2005). Urinary Tract Infection in Adults. Publication No. 06-2097. Bethesda, MD: National Kidney and Urologic Diseases Information Clearinghouse, National Institutes of Health.

Neyestani, T. R., Khalaji, N., and Gharavi, A. (2007). Selective microbiologic effects of tea extract on certain antibiotics against Escherichia coli in vitro. J. Altern. Complement. Med. 13, 1119-1124. doi: 10.1089/ acm.2007.7033

Oliveira, F. A., Paludo, K. S., Arend, L. N. V. S., Farah, S. M. S. S., Pedrosa, F. O., Souza, E. M. et al. (2011). Virulence characteristics and antimicrobial susceptibility of uropathogenic Escherichia coli strains. Genet. Mol. Res. 10, 4114 4125. doi: 10.4238/2011.October. 31.5

Pichon, C., Héchard, C., du Merle, L., Chaudray, C., Bonne, I., Guadagnini, S., et al. (2009). Uropathogenic
Escherichia coli AL511 requires flagellum to enter renal collecting duct cells. Cell Microbiol. 11, 616-628. doi: 10.1111/j.1462-5822.2008.01278.x

Sahm, D. F., Thornsberry, C., Mayfield, D. C., Jones, M. E., and Karlowsky, J. A. (2001). Multidrugresistant urinary tract isolates of Escherichia coli: prevalence and patient demographics in the United States in 2000. Antimicrob. Agents Chemother. 45, 1402-1406. doi: 10.1128/AAC.45.5.1402-1406.2001

Schaeffer, A. J., Klumpp, D. J., Weiser, A. C., Sengupta, S., Forrestal, S. G., and Batler, R. A. (2004). Infectious response to E. coli: molecular and genetic pathways. Int. J. Antimicrob. Agents 24S, S57-S60. doi: 10.1016/j.ijantimicag.2004.02.011

Song, J. M., and Seong, B. L. (2007). Tea catechins as a potential alternative anti-infectious agent. Expert Rev. Anti. Infect. Ther. 5, 497-506. doi: 10.1586/14787210.5.3.497

Stenutz, R., Weintraub, A., and Widmalm, G. (2006). The structures of Escherichia coli $\mathrm{O}$-polysaccharide antigens. FEMS Microbiol. Rev. 30, 382-403. doi: 10.1111/j.1574 6976.2006.00016.x

Taguri, T., Tanaka, T., and Kouno, I. (2004). Antimicrobial activity of 10 different plant polyphenols against bacteria causing food-borne disease. Biol. Pharm. Bull. 27, 1965-1969. doi: 10.1248/bpb.27.1965

Taguri, T., Tanaka, T., and Kouno, I. (2006). Antibacterial spectrum of plant polyphenols and extracts depending upon hydroxyphenyl structure. Biol. Pharm. Bull. 29, 2226-2235. doi: 10.1248/ bpb. 29.2226

Taylor, P. W., Hamilton-Miller, J. M. T., and Stapleton, P. D. (2005). Antimicrobial properties of green tea catechins. Food Sci. Technol. Bull. 2, 71-81.

Vosti, K. L. (2007). A prospective, longitudinal study of the behavior of serologically classified isolates of Escherichia coli in women with recurrent urinary tract infections. J. Infect. 55, 8-18. doi: 10.1016/ j.jinf.2007.01.006

Vuong, Q. V., Nguyen, V., Golding, J. B., and Roach, P. D. (2011). The content of bioactive constituents as a quality index for Vietnamese teas. Int. Food Res. J. 18, 329-336.

Wagenlehner, F. M., and Naber, K. G. (2005). Fluoroquinolone antimicrobial agents in the treatment of prostatitis and recurrent urinary tract infections in men. Curr. Infect. Dis. Rep. 7, 9-16. doi: 10.1007/s11908005-0018-9
Wang, Y., and Ho, C. T. (2009). Polyphenolic chemistry of tea and coffee: a century of progress. J. Agric. Food. Chem. 57, 8109-8114. doi: 10.1021/jf804025c

Warren, J. W., Abrutyn, E., Hebel, J. R., Johnson, J. R., Schaeffer, A. J., and Stamm, W. E. (1999). Guidelines for antimicrobial treatment of uncomplicated acute bacterial cystitis and acute pyelonephritis in women. Infectious Diseases Society of America (IDSA). Clin. Infect. Dis. 29, 745-758. doi: 10.1086/520427

Yam, T. S., Shah, S., and HamiltonMiller, J. M. T. (1997). Microbial activity of whole and fractionated crude extracts of tea (Camellia sinensis), and of tea components. FEMS Microbiol. Lett. 152, 169-174. doi: 10.1111/j.1574-6968.1997.tb10424.x Yang, C. S., Chen, L., Lee, M. J., Balentine, D., Kuo, M. C., and Schantz, S. P. (1998). Blood and urine levels of tea catechins after ingestion of different amounts of green tea by human volunteers. Cancer Epidemiol. Biomarkers Prev. 7, 351-354.

Zhanel, G. G., Hisanaga, T. L., Laing, N. M., DeCorby, M. R., Nichol, K. A., Weshnoweski, B., et al. (2006). Antibiotic resistance in Escherichia coli outpatient urinary isolates: final results from the North American Urinary Tract Infection Collaborative Alliance (NAUTICA). Int. J. Antimicrob. Agents 27, 468-475. doi: 10.1016/j.ijantimicag.2006.02.009

Conflict of Interest Statement: The authors declare that the research was conducted in the absence of any commercial or financial relationships that could be construed as a potential conflict of interest.

Received: 29 August 2012; paper pending published: 03 October 2012; accepted: 31 May 2013; published online: 18 June 2013.

Citation: Reygaert W and Jusufi I (2013) Green tea as an effective antimicrobial for urinary tract infections caused by Escherichia coli. Front. Microbiol. 4:162. doi: 10.3389/fmicb.2013.00162

This article was submitted to Frontiers in Food Microbiology, a specialty of Frontiers in Microbiology.

Copyright (c) 2013 Reygaert and Jusufi. This is an open-access article distributed under the terms of the Creative Commons Attribution License, which permits use, distribution and reproduction in other forums, provided the original authors and source are credited and subject to any copyright notices concerning any third-party graphics etc. 